\title{
ANOTAÇÕES SOBRE O IMPACTO DA COVID-19 NA SAÚDE DA POPULAÇÃO NEGRA
}

\author{
Bas'llele Malomalo ${ }^{1}$ \\ Fara $\mathrm{Vaz}^{2}$ \\ Julian Eduardo Medina-Naranjo ${ }^{3}$
}

\section{Resumo}

São muitos os danos que tem causando a pandemia de COVID-19 e é cedo para saber seu custo real, ainda mais quando os governos têm dificuldades para coordenar políticas efetivas de combate à doença, que evitem o impacto negativo na população geral e, particularmente, nos grupos em situações de mais vulnerabilidade. Este trabalho reflete sobre o impacto da COVID19 na população negra brasileira, começando com os debates feitos por especialistas em Saúde da População Negra e outros agentes sociais no período de abril até maio de 2020. É uma pesquisa documental e bibliográfica que se foca na interpretação temática de conteúdo, dividida em três partes: primeiro, a delimitação do que se entende neste trabalho por população negra; posteriormente, a discussão entre a saúde da população negra e políticas públicas no Brasil; e finalmente, a sistematização do debate sobre o impacto na população negra da COVID-19, destacando as questões de inclusão por cor/raça, gênero e moradia, letalidade, impacto nas periferia, isolamento social e problema de precariedade de vidas negras. Abordam-se ponderações sobre necropolítica e corpos negros/as, índios/as e imigrantes africanos/as; e as

\footnotetext{
${ }^{1}$ Doutor em Sociologia pela UNESP, estagiário pós-doutorado pelo Instituto da Biociência/Departamento de Educação/UNESP-Botucatu, docente e líder do Grupo de pesquisa África-Brasil: Produção de conhecimento, Sociedade civil, Desenvolvimento e Cidadania Global/UNILAB/CNpq, pesquisador do Centro de Ciência e Tecnologia para Soberania e Segurança Alimentar e Nutricional (INTERSSAN-Unesp), do Centro dos Estudos das Culturas e Línguas Africanas e da Diáspora Negra (CLADIN-Unesp), da Rede para o Constitucionalismo Democrático Latino-Americano/Brasil, Pesquisador e membro do Comitê Internacional da Cadeira da Unesco Educação Transformadora, Democracia e Cidadania Mundial, da UQO, Canadá e expert da plataforma Harmony with Nature/ONU e fundador do Instituto da Diáspora Africana no Brasil (IDDAB). Contato: basilele@unilab.edu.br.
}

\footnotetext{
${ }^{2}$ Farã Vaz, graduado em Sociologia e Mestre do programa Interdisciplinar em Humanidades pelo IHL/UNILAB, pesquisador do Grupo de pesquisa África-Brasil: Produção de conhecimento, Sociedade civil, Desenvolvimento e Cidadania Global/UNILAB/CNpq e integrante do MU-CONSAN/UNILAB.
}

${ }^{3}$ Graduado em Licenciatura em Psicologia e Pedagogia pela Universidade Pedagógica Nacional de Colômbia (UPN) em 2007. Mestre do programa de Desenvolvimento Territorial na América Latina e Caribe do Instituto de Políticas Públicas e Relações Internacionais (IPPRI) da Universidade Estadual Paulista "Júlio Mesquita Filho" UNESP. Integrante do Laboratório de Biogeografia e Geografia da Saúde (BIOGEOS) da FCT/UNESP, sob orientação do Professor Livre Docente Raul Borges Guimarães. Integrante do Projeto: Centro de Ciência e Tecnologia para Soberania e Segurança Alimentar e Nutricional (INTERSSAN) - Convênio MCTIC $n^{\circ}$ 821825/2015 - Bolsa de Desenvolvimento Tecnológico e Industrial B (DTI-B) com funções de articulação entre as unidades da UNESP e os países envolvidos na Rede de Soberania e Segurança Alimentar e Nutricional na América Latina (SSAN Latino-América); as universidades do Comitê de Países de Língua Portuguesa (CPLP) e o Grupo de Interesse Especial para a Obesidade (SIG Obesidade) trabalhando na prospecção de parcerias e manutenção da regularidade da comunicação e da informação, apoio com traduções, interpretação de textos e acompanhamento em reuniões. Além de colaboração na logística de eventos desenvolvidos para fortalecer as Redes de SSAN. Diretor/fundador da Associação CASASSA / Casa de Acolhimento LGBT+ em Presidente Prudente. 
propostas de enfretamento da pandemia feitas pela Associação Brasileira de Saúde Coletiva (ABRASCO).

Palavras-chave: População Negra; COVID-19; Saúde da População; Vidas Negras.

\section{Introdução}

A pandemia de COVID-19 causou e vem causando muitos danos à humanidade que não se sabe ainda o seu custo real. O governo brasileiro, como poder executivo, vem tendo dificuldades em coordenar uma política de combate à doença em pauta ao nível nacional, e isso vem causando um impacto negativo na população brasileira e, particularmente, nos grupos em situações de extrema vulnerabilidade.

Esse trabalho pretende refletir sobre o impacto da COVID-19 na população negra brasileira, partindo dos debates feitos pelos/as especialistas em Saúde da População Negra e outros agentes sociais no período de abril até maio. Delimitamos esse período pelo fato de estarmos lidando com um campo movente e dinâmico. Os dados referentes a COVID-19 mudam todo tempo e cada nova informação mexe com as estruturas de toda sociedade.

Para tanto, fundamenta-se numa pesquisa documental e bibliográfica que se foca na interpretação temática de conteúdo. Segundo Antônio Carlos Gil (1996), a pesquisa documental assemelha-se muito à pesquisa bibliográfica. Porém, a diferença essencial entre as duas abordagens está na natureza das fontes. Enquanto essa última utiliza-se, fundamentalmente, das contribuições dos autores sobre determinado assunto, a pesquisa documental vale-se de materiais que não receberam, ainda, um tratamento analítico, ou que ainda possam ser reelaborados, de acordo com os objetivos da investigação. Outra diferença observada por ele, entre ambas é que, geralmente, as fontes da pesquisa bibliográfica são constituídas, sobretudo, de material impresso que são colocadas nas bibliotecas, e hoje, em dia em documentos eletrônicos; já as fontes da pesquisa documental são mais diversificadas e dispersas; são localizadas nos arquivos das instituições não acadêmicas do Estado, do setor privado e da sociedade civil. Nessa pesquisa, trabalhamos com fontes extraídas de jornais eletrônicas e mídias sociais.

As fontes documentais ou bibliográficas manuseadas por nós, trouxeram dados e informações que nos possibilitaram apreender as práticas sociais que estruturam as discussões sobre o impacto de COVID-19 na população negra. As discussões políticas ou teóricas em questão constituem as práticas discursivas (MEDRADO, 1999) dos agentes sociais investigados por nós. Os dados coletados serão organizados a partir do que Gomes (2012) chama de análise temática, antes de proceder à interpretação. Para ele, nesse tipo de análise o conceito central é 
o tema. Esse comporta feixes de relações e pode ser graficamente apresentado através de uma palavra, uma frase, um resumo, um indicador construído pelo pesquisador: O tema é a unidade de significação que se liberta naturalmente de um contexto analisado segundo critérios relativos à teoria que serve de guia à leitura (GOMES, 2012, p. 105). Trabalhar com a análise temática consiste em descobrir os núcleos de sentido que compõem a comunicação e cuja presença, ou frequência de aparição pode significar alguma coisa para o objetivo analítico escolhido (GOMES, 2012, p. 86-87).

O trabalho está dividido em três seções. A primeira delimita o que se entende por população negra nesse trabalho. A segunda discute a relação entre a saúde da população negra e políticas públicas no Brasil. A terceira sistematiza o debate sobre o impacto da COVID-19 na população negra, destacando as questões de inclusão do quesito cor/raça, gênero e moradia, letalidade, seu impacto nas periferias, isolamento social e problema de precariedade de vidas negras; da necropolítica e corpos negros/as, índios/as e imigrantes africanos/as; e as propostas de enfrentamento da pandemia feitas pela Associação Brasileira de Saúde Coletiva (ABRASCO).

\section{O entendimento da população negra nesse trabalho}

Conforme Jaccoud e Beghin (2002, 2009), há duas tendências na conceituação da população negra entre pesquisadores/as brasileiros/as que correspondem as posições ideológicas assumidas pelos grupos envolvidos na disputa da interpretação do Brasil. Para Malomalo (2010), o primeiro grupo tendência neo-freyriana ${ }^{4}$, liderado por maioria de pesquisadores/as brancos/as, acredita que o Brasil é uma democracia racial. Nesse sentido não caberia fazer a soma de pardos/as e pretas para se formar o que se chama de negros/as. Sugere que se continue a usar os termos pardo/a e preto de forma separada. Não aceita o uso do termo raça, e prefere usar o termo etnia. Além disso, é contra que Estado implemente as políticas públicas de cotas e/ou ações afirmativas com recorte na categoria cor/raça.

O segundo grupo de tendência fernandeziana ${ }^{5}$, destaca Malomalo (2010), formado em sua maioria por pesquisadores/as negros/as, com forte atuação no movimento social negro brasileiro, faz uso do termo negro/a para se referir à soma de pardo/a e preto/a, conforme a classificação de Instituto Brasileiro de Geografia e Estatística (IBGE). Publicizando os dados

\footnotetext{
${ }^{4}$ De inspiração teórica do sociólogo brasileiro Gilberto Freyre.

${ }^{5}$ De inspiração teórica do sociólogo brasileiro Florestan Fernandez.
} 
de PNAD (Pesquisa Nacional por Amostra de Domicílios), Bernardo Barbosa ${ }^{6}$ pondera que a proporção de brasileiros/as que se declaram pretos/as, grupo social que, com os pardos/as, forma a população negra, de acordo com os critérios do IBGE foi a única que cresceu em todas as regiões do país entre 2015 e 2018. O que significa que em todo Brasil, o maior aumento em pontos percentuais também era da proporção da população preta, que saiu de 7,4\% em 2012 para 9,3\% seis anos depois. Os pardos/as foram de 45,3\% para 46,5\%. Os brancos, por sua vez, eram $46,6 \%$ da população e chegaram a 43,1\%. Dito em outras palavras, a população negra é composta de $55,8 \%$ brasileiros/as.

Malomalo (2018) e Paixão (2013) fazem observar, em seus estudos, que há quem usa o termo afrodescendente para se referir as pessoas pardas e pretas no Brasil. Nesse contexto, o que importa para esses/as pesquisadores/as é a ascendência, descendência e o pertencimento à história de um povo que foi escravizado, entre outros dos principais motivos, por causa do peso de diferenciações somáticas. As agências da ONU têm usado esse termo e isso veio a ser um termo que possibilitou um certo consenso durante a Conferência Mundial contra o Racismo, Xenofobia e Discriminações Correlatas, que teve lugar em Durban, na África do Sul, em 2001.

Esse segundo grupo de pesquisadores/as, ao interpretar o Brasil, entende que a ideia da democracia étnica de Gilberto Freyre, pautando-se em Florestan Fernandez que a nomeou de democracia racial, é um mito (MALOMALO, 2010; PAIXÃO, 2006). Isto é, uma falsa ideia sobre o Brasil como um paraíso racial. Nesse sentido, em seus estudos sociológicos, tende a utilizar as categorias cor/raça para compreender as dinâmicas sociais de pertencimento, de identidade, de território, de mobilidade social e/ou de desigualdades sociais no acesso aos direitos da cidadania. Defende as políticas públicas de cotas e ações afirmativas para grupos raciais historicamente discriminados no país.

Os estudos, realizados por esse segundo grupo, defendem que para se compreender as desigualdades sociais, no Brasil, é preciso desvendar os mecanismos do racismo (GUIMARÃES, 2001; GOMES, 2005). Esses mecanismos igualmente são compreendidos quando se leva a sério categorias de raça nos estudos sociais. Nesse sentido, a percepção, não somente nas estatísticas, mas igualmente nas pesquisas de ordem qualitativas, de que as desigualdades sociais entre pessoas brancas em relação às pardas e às negras fez com que intelectuais e ativistas do Movimento Negro passassem a usar, desde os anos de 1970, o termo

\footnotetext{
${ }^{6}$ BARBOSA, Bernardo. Número de brasileiros que se declaram pretos cresce no país, diz IBGE. UOL Cotidiano, 22 maio 2019. Disponível em: https://noticias.uol.com.br/cotidiano/ultimas-noticias/2019/05/22/ibge-em-todasas-regioes-mais-brasileiros-se-declaram-pretos.htm. Acesso em: 24 abr. 2020.
} 
negro para se referir às pardas/os e pretas/os. Nesse entendimento, além de ser uma categoria analítica, o negro é uma categoria política de resistência contra a opressão racista e reivindicação de políticas públicas de igualdade racial.

Com a insistência de intelectuais negros/as, brancos/as antirracistas e dos grupos negros organizados, que formam o Movimento Negro, a maioria de pesquisadores/as brasileiros/as e as agências como o Instituto de Pesquisa e Estatística Aplicada (IPEA) passaram a usar o termo negro para se referir à população formada por pessoas pardas e pretas (GOMES, 2005; PAIXÃO, 2013).

Contudo, há igualmente um certo cuidado, nesse grupo, em desagregar pardos/as e pretos/as em alguns estudos (PAIXÃO, 2006, 2013; PAIXÃO; CARVANO, 2008). Tudo isso, levando-se em conta a dimensão cromática do racismo à brasileira. Isso que Oracy Nogueira (1985) chamou de preconceito de marca e preconceito de origem, ao comparar o racismo existente nos Estados Unidos e no Brasil. Para ele, o primeiro preconceito, presente no Brasil valoriza ou desvaloriza uma pessoa conforme a tonalidade da pele. Quando mais claro, entendase branco/a, passa-se a ser mais valorizado/a; quando mais escuro se é, entende-se mais o fenótipo africano se carrega no seu corpo, mais rejeição passa-se a sofrer. Do lado oposto, para ele, nos Estados Unidos, o racismo opera pela origem da pessoa independentemente de ser mais clara ou mais escura, isto é, quando uma pessoa tem uma gota de sangue negro na família independentemente de que grau geracional, essa passa automaticamente a pertencer ao grupo de negros/as. Nogueira reconhece que as duas categorias que ele apresenta são os tipos ideias e, às vezes, os dois se misturam num país como no outro.

Nessa linha é que, quando situado nesse segundo grupo da interpretação das relações raciais, desagregam-se os termos pardo/a e preto com intuito de perceber as diferenças que as tonalidades de cor da pele possam vir a estabelecer entre a população negra. Além disso, o debate atual sobre a identidade de pessoas negras, no país, devido às fraudes que vêm acontecendo em relação às políticas de cotas da parte de uma parcela de uma população socialmente vista como branca/a, tem levado um bocado de intelectuais e ativistas pretos/as a questionar a legitimidade analítica e política de continuar a se manter o termo negro como a soma de pardo/a e preto de IBGE (DOSSIÊ TEMÁTICO, 2019). Recusam igualmente o emprego do termo afrodescendente que acham aberto demais e, portanto, não operacional politicamente. Sendo assim, reivindicam o termo negro somente para pessoas que consideram como pretas, excluindo negros/as de cor mais clara. Portanto, a polêmica sobre o colorismo ou 
pigmentocracia tem ocupado o palco dos debates. Pessoas negras de cor de pele mais clara têm se sentido desconfortáveis nesse debate ${ }^{7}$.

A população de imigrantes negros/as no Brasil é, muitas vezes, ignorada pelos dois grupos de pesquisadores/as que acabamos de mencionar (MALOMALO, 2018). Dito em outras palavras, tudo se passa como se àquelas populações vindas da África ou de outras partes do mundo, especialmente de América Central, Caribes e América do Sul não fossem sujeitos que interessassem aos estudos das relações raciais no Brasil. Com poucas exceções, percebe-se o cruzamento dos aportes teóricos entre os estudos raciais e os estudos migratórios feitos no Brasil. O que temos percebido é que são pesquisadores/as africanos/as formados/as em Ciências sociais no Brasil, que quando estudam as populações africanas tendem a fazer esse cruzamento teórico que é, ao mesmo tempo, um exercício político (MALOMALO, 2017, 2018). Nesse sentido, queremos deixar claro que nos interessa nesse trabalho a população de imigrantes africanos/as dentro do que é chamada de população negra no Brasil. Deixaremos de lado imigrantes negros/as oriundos/as de outros territórios geográficos já sinalizados. A imigração africana gira entre 30 a 40 mil pessoas no Brasil.

Nós usamos negros ou afrodescendentes, pautando em Malomalo (2018), como sinônimos, assumindo todas as limitações analíticas e políticas que eles comportam. Usamos como a soma de pessoas pardas/os e pretas/ de IBGE. Levando em conta a concepção da União Africana A e da UNESCO, consideramos os/as imigrantes africanos/as como parte da diáspora brasileira. Todavia, reconhecemos as diferenças que existem entre negros/as nascidos/as no Brasil e africanos/as que vieram desde século XX como imigrantes.

\section{Saúde da população negra e políticas públicas no Brasil}

O campo de saúde da população negra no Brasil é algo muito recente no país. A sua expansão acompanhou a movimentação da militância negra em todos setores da nação. Como nos alertaram Alberto Luis Gonçalves e Petronilha Beatriz Gonçalves e Silva (2003, 2006), as lutas das populações negras caminharam dos protestos de rua, dos anos de 1970, para políticas públicas que começaram a se desenhar entre os anos de 1980 e 1990, com a ascensão do multiculturalismo no mundo e no país.

\footnotetext{
${ }^{7}$ SILVA, Gabriele de Oliveira da. As não Brancas- Identidade Racial e Colorismo no Brasil. Portal Geledés, 18 abr. 2020. Disponível em: https://www.geledes.org.br/as-nao-brancas-identidade-racial-e-colorismo-no-brasil/. Acessado em: 5 maio 2020.
} 
O que aconteceu é que a Constituição de 1988 passou a reconhecer o Brasil como um país pluriétnico (PAIXÃO, 2007; THEODORO, 2008). Nesse sentido, além de sinalizar a adoção de políticas públicas de enfoque universalista, reconhece a necessidade de outras de dimensão focada, ou seja, políticas públicas voltadas para grupos étnico-raciais negros e indígenas. O Estado brasileiro comprometeu-se em trabalhar pela ampliação da cidadania para negros/as, quilombolas, indígenas protegendo-os como sujeitos de direitos e protegendo seus patrimônios coletivos que fazem parte da nação brasileira.

No que diz respeito a população negra, começaram a emergir fundações, coordenadorias e secretarias, grupos de trabalhos para atender suas demandas. Nessa linha, instauram-se, por exemplo, a Fundação Palmares no âmbito Federal, Coordenadoria dos Assuntos da População Negra no Governo de São Paulo, Grupo de Trabalho de Saúde da População negra no Município de São Paulo.

O livro Saúde da população negra (2012) nos oferece oportunidade para conhecer a história da consolidação dessa área de conhecimento e a emergência de políticas públicas a respeito, no seu texto de "Apresentação da primeira edição do livro", escrito por Batista, Werneck e Lopes (2012) destaca com detalhes esses elementos. Para este autor, a história de consolidação do campo de conhecimento da saúde da população negra está ligada com a história do Congresso de Pesquisadores Negros (COPENE), cuja primeira edição teve lugar em 2000, na Universidade Federal de Pernambuco, Recife. Naquele ano o tema do Congresso foi "O Negro e a Produção do Conhecimento: dos 500 anos ao Século XXI”. Nessa ocasião, Luís Eduardo Batista e Maria Inês da Silva Barbosa foram responsáveis em coordenar a área saúde e articular pesquisadores negros que atuavam na área dado que, dos 320 participantes do I COPENE, não mais do que doze produziam neste campo de conhecimento. Para melhor articular a temática saúde na ABPN, foi estabelecida parceria com integrantes do Grupo de Trabalho Interministerial para Valorização da População Negra (GTI - subtema Saúde), criado pelo governo federal em resposta às reivindicações apresentadas pelo movimento negro durante a Marcha Zumbi dos Palmares Contra o Racismo, pela Cidadania e a Vida, que tinha ocorrido em novembro de 1995.

Em dezembro de 2001, escreve Batista, Werneck e Lopes (2012), após a realização da III Conferência Mundial de Combate ao Racismo, Discriminação Racial, Xenofobia e Intolerâncias Correlatas, membros do GTI-saúde, pesquisadoras, pesquisadores e ativistas organizaram, com o apoio do Sistema das Nações Unidas, o Workshop Interagencial Saúde da População Negra, cujo resultado foi a publicação "Política Nacional de Saúde da População 
Negra, uma Questão de Equidade: subsídios para o debate" e a recomendação de uma consultoria para compilar e sistematizar informações sobre o tema, que resultou no livro Saúde da População Negra no Brasil, de autoria da médica Fátima Oliveira.

Em 2003, prossegue Batista, Werneck e Lopes (2012), o apoio da Secretaria de Políticas de Promoção da Igualdade Racial (SEPPIR) e do Programa de Combate ao Racismo Institucional, conta Luís Eduardo Batista, possibilitou converter as recomendações do II Copene em propostas para XII Conferência Nacional de Saúde (realizada em dezembro de 2003). E, nessa ocasião, pela primeira vez na história das Conferências de Saúde a temática saúde da população negra foi incorporada ao relatório final.

Em setembro de 2004, Batista, Werneck e Lopes (2012) relata que vivenciava-se um novo momento político que era marcado pela esteira do PCRI, em resposta ao desafio de contribuir para o alcance de um dos objetivos do governo federal que era a redução das desigualdades raciais e de gênero, à ação sistemática da SEPPIR, às deliberações da Conferência Nacional de Saúde e às reivindicações de ativistas e pesquisadoras negros/as e aliados/as, o Ministério da Saúde incorporava o tema saúde da população no plano nacional de saúde; criava-se o Comitê Técnico de Saúde da População Negra cuja principal atribuição era assessorar o Mistério da Saúde na formulação e implementação de políticas, ações e programas com uma perspectiva de equidade racial. Realizou-se, nesse contexto, o I Seminário Nacional de Saúde da População Negra e apoia, por meio da Fundação Nacional de Saúde (FUSNASA), a elaboração da publicação "Saúde da População Negra no Brasil: contribuições para Promoção da Equidade".

O mesmo ano de 2006, ressalta Batista, Werneck e Lopes (2012) que foi marcado por uma grande vitória no campo da saúde da população negra: em novembro, o Conselho Nacional de Saúde aprovou a Política Nacional de Saúde Integral da População Negra. Apesar dessa aprovação, em 2006, nos alerta o autor, àquela política só foi pactuada na Comissão Intergestores Tripartite em 2008 e publicada por meio de portaria ministerial aos 13 de maio de 2009 (Portaria no 992 do Ministério da Saúde). É importante destacar, prossegue o autor, que uma das marcas da PNSIPN é "o reconhecimento do racismo, das desigualdades étnico-raciais e do racismo institucional como determinantes sociais e condições de saúde, com vistas à promoção da equidade em saúde" (BATISTA; WERNECK; LOPES, 2012, p. 14-15), e o reconhecimento, por parte do Ministério da Saúde, de que as condições de vida da população negra impactam o processo saúde, doença e morte. 
Sandra Assis Brasil e Leny Alves Bomfim Trad (2012), na sua investigação, observam que se organizou no país, em fins do século XX e início do século XXI, uma agenda voltada à saúde da população negra. Entre outras conquistas que ocorreram devido a luta do movimento social negro, mencionam a incorporação de identificação da população, raça, cor e etnia que, aliadas aos dados censitários e epidemiológicos, confirmariam injustiças e iniquidades em saúde de uma parcela da população brasileira e forçariam o Estado a conceber uma política pública, em consonância com o SUS: a Política Nacional de Saúde Integral da População Negra, com vistas à promoção da equidade racial em saúde.

Essa política, reiteram Brasil e Trad (2012), advinha de um processo histórico reforçado por atuações de diversas organizações e movimentos sociais, em especial o movimento negro. Tais ações, voltadas à valorização da população negra, reivindicaram a inclusão e abordagem das questões raciais na saúde. Os documentos lançados nesse processo contribuíram para o estabelecimento de padrões de equidade étnico-racial na política de saúde do país e para o reconhecimento oficial, pelo Estado brasileiro, do racismo institucional nas instâncias do SUS.

A política de Saúde da População Negra, para Brasil e Trad (2012), enquanto política transversal, está intimamente relacionada com os princípios e diretrizes do SUS. Seu desafio é garantir, afirmam as autoras, a transversalidade das questões étnico-raciais no setor da saúde, bem como combater o racismo institucional nas instâncias do SUS. O combate ao racismo no seio de uma política pública pareceu-lhes uma grande provocação para a sociedade brasileira, centrada na visão de que ou o racismo não existe, ou não é um problema de todos. Assim, analisaram um processo em que se conjugavam elementos de governo, orientações de Estado, mas, sobretudo, um processo que se conformava na contramão da ideologia do racismo e da democracia racial, dentro de um ambiente político.

Ponderam que as questões raciais vêm sendo debatidas há muito, por diversos/as estudiosos/as das relações raciais brasileiras. Porém, observam que, no âmbito das políticas públicas, o processo de discussão e assunção dessas temáticas pelo Estado brasileiro demandavam um tempo maior de confronto e convencimento sobre a pertinência dessas questões na elaboração de soluções em políticas públicas. Era preciso, portanto, avaliar a efetividade e a aderência das ações e políticas voltadas à população negra.

Entretanto, há que se pensar, prosseguem Brasil e Trad (2012), sobre os limites da atuação das políticas públicas e do Estado brasileiro não apenas com a temática das relações raciais, mas também os limites institucionais dessas esferas de atuação. Os dilemas em torno do racismo e dos outros problemas que afetam a população negra brasileira, questionam elas, 
seriam resolvidos meramente dentro da esfera institucional? Para responder a sua pergunta, ponderam que outros espaços e instâncias poderiam e deveriam ser acionados. Embora, seja o Estado o responsável direto pela garantia da lei e dos direitos humanos inalienáveis, a presença da lei e do papel é apenas o início da luta, finalizam elas.

Na ocasião que escreviam seu texto, Brasil e Trad (2012) perceberam que a Política Nacional de Saúde Integral da População Negra se encontrava em um momento delicado de mudanças no governo e alterações nos modos de concebê-la dentro do próprio Ministério da Saúde. O contexto nacional apontava um processo de esvaziamento da SEPPIR, tornando-a pouco atuante e o Comitê Técnico de Saúde da População Negra com pouca força política.

Os/as entrevistados/as de Brasil e Trad (2012) assinalavam, na época, retrocessos nas discussões raciais por causa da aprovação de uma versão do Estatuto da Igualdade Racial cheio de vetos em muitos pontos, inclusive relacionados à saúde e uma perda significativa de lideranças do movimento negro para a composição dos quadros de gestão.

Portanto, Brasil e Trad (2012) percebiam muitos os desafios para uma efetiva implementação da PNSIPN. O primeiro deles correspondia ao modo como deverá atingir o cotidiano das unidades de saúde, já que o enfrentamento ao racismo precisava ser realizado junto aos profissionais, gestores e sociedade civil de uma nação "racialmente democrática". Além disso, era preciso que a política de SPN ganhasse os espaços das ruas, das praças, que ela fosse além dos meandros restritos da dimensão do poder político estatal, ou não seja apenas uma questão de negros, da militância negra, necessitando se expandir entre outros movimentos sociais.

As dificuldades apontadas pela Brasil e Trad (2012) iniciaram no governo Dilma, passando pelo seu agravamento no governo Temer e, por fim, no governo de Bolsonaro, fundamentado no negacionismo de tudo e na cegueira sobre o racismo estruturante das relações sociais, isto é, o ciclo de vida de nascer, adoecer e morrer.

\section{COVID-19 e a saúde da população negra: debates e embates}

Pretendemos, nessa seção, com base em documentos e textos destacar os principais pontos que compõem o debate sobre o impacto de COVID-19 na população negra, no período de março até maio de 2020. 
É importante começar refletindo sobre a inclusão do quesito cor/raça, gênero e moradia. A Associação Brasileira de Saúde Coletiva $(\mathrm{ABRASCO})^{8}$, na sua publicação que data de 11/04/2020, informa que a matéria da Folha de São Paulo ressaltou que a Coalizão Negra por Direitos e o Grupo de Trabalho de Saúde da População Negra da Sociedade Brasileira de Medicina de Família e Comunidade (SBMFC) entraram, em separado e por vias distintas, com pedidos ao Ministério da Saúde para a inclusão de campos específicos de raça, gênero e moradia desagregada por bairros nos municípios, nas notificações obrigatórias para SRAG e demais enfermidades relacionadas à COVID-19.

\begin{abstract}
“Assim como nos Estados Unidos fica evidente que a população periférica, majoritariamente composta por pessoas negras, é mais afetada pela Covid-19, é importante que tenhamos esses dados categorizados por raça e cor no Brasil para tomar providências", afirma Denize Ornellas, diretora da SBMFC. Outra matéria do mesmo veículo de comunicação aponta que a pasta da saúde deverá abraçar as demandas. No entanto, não há na matéria fonte oficial do Ministério, nem uma notícia específica no site da autarquia ${ }^{9}$.
\end{abstract}

ABRASCO, através do seu Grupo de Trabalho Racismo, entende que a crise da pandemia está relacionada com a cor/raça e o gênero. Nesse sentido é que pautou este debate no artigo da colunista Flávia Oliveira do jornal $O$ Globo, publicado na sexta, dia 10 de abril. A jornalista fundamentou a sua argumentação no cenário da pandemia nos Estados Unidos e nas discrepantes taxas de óbitos entre brancos/as e negros/as naquele país. Apontou que, por exemplo, na cidade Chicago, estado de llinois, que comporta um terço da população composta por afro-americanos/as, corresponde a $72 \%$ dos óbitos motivados pela pandemia ${ }^{10}$.

Os/as especialistas em Saúde da População Negra, ao perceber o descaso do Ministério da Saúde em trazer dados com recortes de cor/raça, engajaram-se em denunciar e tomar medidas judiciais.

"Lá como cá, as estatísticas sobre incidência da pandemia por cor ou raça são deficientes. No Brasil, contaminações leves ou assintomáticas mal foram detectadas; faltam testes. Nas fichas de comunicação obrigatória dos casos graves, a informação sobre etnia é quase sempre negligenciada. Isso, até

\footnotetext{
${ }^{8}$ DIAS, Bruno C. Letalidade da Covid-19 na população negra pauta debate sobre raça e desigualdades. Rio de Janeiro: ABRASCO, 2020. Disponível em: https://www.abrasco.org.br/site/noticias/saude-dapopulacao/letalidade-da-covid-19-na-populacao-negra-pauta-debate-sobre-raca-e-desigualdade-social-naimprensa/46775/. Acesso em: 4 Jun. 2020.

${ }^{9}$ DIAS, Bruno C. Letalidade da Covid-19 na população negra pauta debate sobre raça e desigualdades. Rio de Janeiro: ABRASCO, 2020. Disponível em: https://www.abrasco.org.br/site/noticias/saude-dapopulacao/letalidade-da-covid-19-na-populacao-negra-pauta-debate-sobre-raca-e-desigualdade-social-naimprensa/46775/. Acesso em: 4 Jun. 2020.

${ }^{10}$ Ibidem.
} 
agora, inviabilizou a produção de dados sobre o perfil racial dos doentes por Ministério da Saúde, governos estaduais e prefeituras. Não à toa, a Coalização Negra por Direitos reivindicou em documento assinado por 150 organizações a apresentação dos recortes racial e de gênero. Pleito semelhante fez a Associação Brasileira de Saúde Coletiva (ABRASCO) em relatório com uma dúzia de recomendações para o enfrentamento à pandemia", traz o texto de opinião ${ }^{11}$.

De fato, a introdução do quesito cor/raça já tinha se consolidado em um direito adquirido, validado pelo Ministério da Saúde, desde os anos de 2017, através da Portaria n 344 GM/MS, de 01 de fevereiro de 2017, que dispõe sobre a inclusão e o preenchimento do quesito raça/cor nos formulários dos sistemas de informação em saúde ${ }^{12}$. Acontece que com a ascensão do governo neoliberal de extrema direita, no Brasil, as políticas de igualdade racial e de gênero foram atacadas.

Para a Pública $^{13}$, foi o grupo de trabalho de saúde da população negra, da qual Borret faz parte, que pediu ao Ministério da Saúde que publicasse dados de raça/cor de mortos por coronavírus. O governo só passou a divulgar os dados no boletim referente a 11 de abril, sem detalhar dados de casos confirmados ou de testes. Questionado sobre a falta de dados mais completos, o ministério, já sob a gestão de Nelson Teich, chegou a afirmar que não haveriam estudos técnicos ou científicos que apontassem cor ou raça como fator de risco da doença.

A reação da médica e especialista da Saúde da População Negra, Borret, foi essa:

Nós sabemos disso, o problema não é raça, mas o racismo, que dificulta o acesso de negros à saúde. $\mathrm{O}$ acesso à saúde da população negra é muito pior que da população branca no país. E a gente não tem tempo, o coronavírus não dá tempo para fazermos um trabalho pedagógico sobre a Política Nacional de Saúde Integral da População Negra. Precisamos que o Ministério esteja atento a essas questões o tempo todo, como está escrito na Lei $[\ldots]^{14}$.

É preciso notificar que, com a pressão das organizações do movimento social negro e entidades de defesa de direito à saúde pública, a justiça obrigou o governo a usar os recortes de

\footnotetext{
${ }^{11}$ Ibidem.

12 ABRASCO. Carta ao Ministério da Saúde sobre a informação raça/cor nos sistemas de informação da Covid-19. Rio de Janeiro: ABRASCO, 2020. Disponível em: https://www.abrasco.org.br/site/noticias/posicionamentos-oficiais-abrasco/carta-ao-ministerio-da-saude-sobre-ainformacao-raca-cor-nos-sistemas-de-informacao-da-covid-19/47320/. Acesso em: 2 maio 2020.

13 MUNIZ, Bianca; FONSECA, Bruno, PINA, Rute. Em duas semanas, número de negros mortos por coronavírus é cinco vezes maior no Brasil. São Paulo: Pública Agência de Jornalismo Investigativo, 2020. Disponível em: https://apublica.org/2020/05/em-duas-semanas-numero-de-negros-mortos-por-coronavirus-ecinco-vezes-maior-no-brasil/. Acessado em 06 maio 2020

${ }^{14}$ Ibidem.
} 
raça e gênero no combate a COVID-19. A partir de 10 de abril de 2020, o governo, através do Ministério da Saúde, sinalizava a divulgação dos infectados por raça/cor ${ }^{15}$.

Outro assunto central no debate é a população de risco e comorbidades. Nos debates atuais, o racismo, as desigualdades sociais e a comorbidade aparecem como fatores de agravamento do impacto da COVID-19 na população negra.

De acordo com Denize Ornella, dos brasileiros/as que dependem exclusivamente de SUS, 67\% são negros, e são esses a maioria de pacientes com diabetes, tuberculose, hipertensão e doenças renais crônicas no país. Todas essas doenças são consideradas agravantes para se desenvolver casos mais gravosos da COVID-19 ${ }^{16}$.

Lúcia Xavier, assistente social e presidente da organização da sociedade civil negra, Crioula, de outro lado, corroborando o pensamento da maioria de pesquisadores/as em Saúde da População Negra, salienta que a maioria de casos de comorbidades citados, são ligados às questões sociais como falta de saneamento básico, e agravadas pelas desigualdades raciais, condições precárias de moradias, que favorecem doenças como tuberculose, ou alimentação inadequada, que promovem doenças como diabetes e hipertensão arterial. Nesse sentido, para ela, essas condições socioeconômicas geram maior vulnerabilidade em saúde da população negra durante a pandemia. Além disso, com o sucateamento do SUS, negros/as terão dificuldades em receber um atendimento adequado ${ }^{17}$.

O outro assunto em debate é a questão da maior letalidade entre negros/as apesar de serem a minoria entre os contaminados desde que a pandemia começou a ser investigada em março. A ABRASCO em sua matéria "Letalidade da Covid-19 na população negra pauta imprensa sobre raça e desigualdades", publicado em 11 de abril de $2020^{18}$, relata o que segue:

\footnotetext{
${ }^{15}$ BORGES, Pedro. Covid-19: Ministério da Saúde divulgará dados de infectados por raça/cor. Alma Preta Jornalismo preto \& livre, 10 abr. 2020. Disponível em: https://almapreta.com/editorias/realidade/covid-19ministerio-da-saude-divulgara-dados-de-infectados-por-raca-cor. Acesso em: 5 maio 2020.

${ }^{16}$ MENA, Fernanda. Entre casos identificados, covid-19 se mostra mais mortífera entre negros no Brasil, apontam dados. Folha de São Paulo, São Paulo, 10 abr. 2020. Cotidiano. Disponível em: https:/www1.folha.uol.com.br/cotidiano/2020/04/coronavirus-e-mais-letal-entre-negros-no-brasil-apontamdados-da-saude.shtml Acesso em: 4 jun. 2020.

${ }^{17}$ Ibidem.

${ }^{18}$ DIAS, Bruno C. Letalidade da Covid-19 na população negra pauta debate sobre raça e desigualdades. Rio de Janeiro: ABRASCO, 2020. Disponível em: https://www.abrasco.org.br/site/noticias/saude-dapopulacao/letalidade-da-covid-19-na-populacao-negra-pauta-debate-sobre-raca-e-desigualdade-social-naimprensa/46775/. Acesso em: 4 Jun. 2020.
} 
Embora minoritários entre os registros de afetados pela Covid-19, pretos e pardos representam quase 1 em cada $4(23,1 \%)$ dos brasileiros hospitalizados com Síndrome Respiratória Aguda Grave (SRAG, em português; SARS, em inglês), mas chegam a 1 em cada 3 entre os mortos infectados pelo novo coronavírus $(32,8 \%)$. Já com a população branca ocorre o contrário: são 73,9\% entre aqueles hospitalizados com Covid- 19 , mas $64,5 \%$ entre os mortos ${ }^{19}$.

Os dados acima foram apresentados durante coletiva do Ministério da Saúde realizada na sexta-feira, 10 de abril de 2020.

Em 06 de maio de 2020, Pública, na sua matéria "Em duas semanas, número de negros mortos por coronavírus é cinco vezes maior no Brasil" ${ }^{20}$, situava-nos sobre algo que se temia: o aumento da letalidade no meio da população negra.

Em duas semanas, a quantidade de pessoas negras que morrem por Covid-19 no Brasil quintuplicou. De 11 a 26 de abril, mortes de pacientes negros confirmadas pelo Governo Federal foram de pouco mais de 180 para mais de 930. Além disso, a quantidade de brasileiros negros hospitalizados por Síndrome Respiratória Aguda Grave (SRAG) causada por coronavírus aumentou para 5,5 vezes.

Já o aumento de mortes de pacientes brancos foi bem menor: nas mesmas duas semanas, o número chegou a pouco mais que o triplo. E o número de brasileiros brancos hospitalizados aumentou em proporção parecida.

A explosão de casos de negros que são hospitalizados ou morrem por Covid19 tem escancarado as desigualdades raciais no Brasil: entre negros, há uma morte a cada três hospitalizados por SRAG causada pelo coronavírus; já entre brancos, há uma morte a cada 4,4 hospitalizações ${ }^{21}$.

O trecho acima revela que o aumento de mortalidade entre pessoas negras por COVID19 é uma evidência que o poder público deve levar em conta. Entre outras explicações encontradas pelos/as especialistas da Saúde da População Negra, o racismo vem sendo apontado como um dos fatores agravantes ${ }^{22}$.

\footnotetext{
${ }^{19}$ Ibidem.
}

${ }^{20}$ MUNIZ, Bianca; FONSECA, Bruno, PINA, Rute. Em duas semanas, número de negros mortos por coronavírus é cinco vezes maior no Brasil. São Paulo: Pública Agência de Jornalismo Investigativo, 2020. Disponível em: https://apublica.org/2020/05/em-duas-semanas-numero-de-negros-mortos-por-coronavirus-ecinco-vezes-maior-no-brasil/. Acessado em 06 maio 2020.

${ }^{21}$ Ibidem.

${ }^{22}$ MARTINS, Pedro. População negra e Covid-19: desigualdades sociais e raciais ainda mais expostas. Rio de Janeiro: ABRASCO, 2020. Disponível: https://www.abrasco.org.br/site/noticias/sistemas-de-saude/populacaonegra-e-covid-19-desigualdades-sociais-e-raciais-ainda-mais-expostas/46338/. Acesso em: 31 maio 2020. 
A tabela abaixo nos permite afirmar que as desigualdades raciais não estão somente durante o período de adoecimento, mas igualmente de morte.

Tabela 1: Hospitalizações e óbitos por Covid-19 segundo raça/cor - maio 2020

\begin{tabular}{|l|c|c|}
\hline & Hospitalizações* & Óbitos** \\
\hline Branca & $49,0 \%$ & $41,0 \%$ \\
\hline Parda & $42,0 \%$ & $49,6 \%$ \\
\hline Preta & $7,1 \%$ & $7,4 \%$ \\
\hline Amarela & $1,6 \%$ & $1,6 \%$ \\
\hline Indígena & $0,3 \%$ & $0,5 \%$ \\
\hline
\end{tabular}

Fonte: *Sistema de Informação de Vigilância da Gripe. Ministério da Saúde. Dados atualizados em 25 de maio de 2020 às $10 \mathrm{~h}$, sujeitos a revisões. *Excluídos 19.226 casos com variável raça/cor ignorada.

Fonte: **Sistema de Informação de Vigilância da Gripe. Ministério da Saúde. Dados atualizados em 25 de maio de 2020 às $10 \mathrm{~h}$, sujeitos a revisões. *Excluídos 6.245 óbitos com variável raça/cor ignorada.

A tabela apresentada acima sinaliza dados recentes sobre as hospitalizações por Síndrome Respiratória Aguda Grave (SRAG) por COVID-19 segundo raça/cor. Brasil, no período de 25 de maio de 2020, e os casos de óbitos por Síndrome Respiratória Aguda Grave (SRAG) por COVID-19 segundo raça/cor. Percebe-se que, nesse período, foram hospitalizados por motivo SRAG por COVID-19 49,1\% de negros/as e 49\% de brancos/as, e entre os mortos têm-se $57,0 \%$ de negros/as contra $41 \%$ de brancos. Há, portanto, uma diferença de $16 \%$ a favor de brancos/as e em detrimento de negros/as.

Poderia ter relevância neste debate a relação da periferia e a população negra? A ABRASCO sinaliza que o seu Grupo Temático Racismo e Saúde (GT Racismo/ABRASCO) já havia apontado a possibilidade da COVID-19 chegar nas periferias, com muita preocupação na matéria "População negra e Covid-19: desigualdades sociais e raciais ainda mais expostas"23, produzida pela Comunicação da ABRASCO e publicada em 31 de março, no conjunto de materiais do Especial Abrasco Coronavírus. Infelizmente, pondera a matéria que os dados atuais já indicam que o coronavírus chegou às periferias antes do que se pensava. Além disso, reforçam o fato de que as questões relacionadas à saúde e às doenças nas sociedades têm forte determinação social e racial.

"Com 20 dias desde o primeiro óbito, termos $32 \%$ das mortes entre pessoas negras indica que o isolamento social não retardou a chegada do coronavírus nas periferias como esperávamos. A epidemia começou com uma elite, majoritariamente branca, mas que tem sua cozinheira, sua faxineira, seus

\footnotetext{
${ }^{23}$ DIAS, Bruno C. Letalidade da Covid-19 na população negra pauta debate sobre raça e desigualdades. Rio de Janeiro: ABRASCO, 2020. Disponível em: https://www.abrasco.org.br/site/noticias/saude-dapopulacao/letalidade-da-covid-19-na-populacao-negra-pauta-debate-sobre-raca-e-desigualdade-social-naimprensa/46775/. Acesso em: 4 Jun. 2020.
} 
cuidadores, majoritariamente negros" disse Luis Eduardo Batista, pesquisador do Instituto da Saúde da Secretaria de Saúde do Estado de São Paulo, diretor do Conselho Deliberativo da Associação e integrante da coordenação do GT Racismo/Abrasco, ao jornal Folha de S. Paulo na matéria Coronavírus é mais letal entre negros no Brasil, apontam dados da Saúde ${ }^{24}$.

A agência Pública ${ }^{25}$, cruzando os dados de raça/cor com a questão territorial nas zonas urbanas de São Paulo, faz observar que para cada morte em Moema (bairro nobre), quatro morrem na Brasilândia (bairro periférico). Revela com isso que em São Paulo, na maior cidade do país e a que conta com maior número de mortes por Covid-19, são os bairros onde a população negra está mais concentrada que trazem a maior quantidade de óbitos pela doença. Segundo a Pública apurou, dos dez bairros com maior número absoluto de mortes causadas pelo coronavírus, oito têm mais negros/as que a média de São Paulo.

Dito em outras palavras, o bairro que concentra o maior número absoluto de mortes é a Brasilândia, com 103 casos. A região tem cerca de 50\% da população negra — a média de São Paulo é de $37 \%$. No extremo oposto, o bairro que tem menos números de negros/as da cidade, Moema, teve 26 mortes. A média de negros na região é de menos de $6 \%{ }^{26}$.

A periferia significa igualmente residir num território sem equipamentos de saúde apropriados para atender os/as doentes de COVID-19. É o que acontece em Amazonas, conforme a Pública $^{27}$, com colapso do Sistema Único de Saúde (SUS), brancos sobrevivem mais que negros. Ou seja, nesse território periférico do Brasil, entre as pessoas que desenvolvem quadros graves da COVID-19, são mais frequentes mortes de negros/as que brancos/as. Segundo a Pública apurou, a cada 2,4 negros em estado grave, há uma morte. Já entre brancos/as, uma morte foi registrada a cada 3,2 pacientes em situação grave.

O estado, que foi o primeiro a ter lotação máxima de unidades de terapia intensiva para pacientes com COVID-19, alerta a Pública $^{28}$, tem registrado um aumento mais expressivo entre

\footnotetext{
${ }^{24}$ Ibidem.

25 MUNIZ, Bianca; FONSECA, Bruno, PINA, Rute. Em duas semanas, número de negros mortos por coronavírus é cinco vezes maior no Brasil. São Paulo: Pública Agência de Jornalismo Investigativo, 2020. Disponível em: https://apublica.org/2020/05/em-duas-semanas-numero-de-negros-mortos-por-coronavirus-ecinco-vezes-maior-no-brasil/. Acessado em 06 maio 2020.

${ }^{26}$ Ibidem.

${ }^{27}$ Ibidem.

${ }^{28}$ Ibidem.
} 
negros/as em estado grave que entre brancos/as. No final de abril, como já mencionamos, em menos de uma semana, a quantidade de pacientes negros/as em situação grave mais que dobrou.

Pública $^{29}$ finaliza a sua matéria afirmando que a maioria absoluta das mortes, no Amazonas, são de negros/as. O que significa que, no período analisado, mais de 13 negros/as morreram para cada falecimento de branco/a. A Secretaria de Saúde já registrava cerca de 850 doentes negros/as em situação grave e mais de 340 mortes. Já entre brancos/as, foram registrados 81 casos graves e 25 mortes.

Um outro problema que aparece nos debates sobre o impacto da COVID-19 na população negra é o fato da maioria dessa população encontrar-se em situação de precariedade no mercado de trabalho formal e informal e compor a grande massa de desempregados/as do país. Ao se decretar o isolamento social sem, todavia, implementar-se políticas sociais de emergência para proporcionar recursos a essa população, a maioria de suas famílias viu-se obrigada a não respeitar as leis, saindo para rua para vender seus produtos.

Ao entrevistar o jornalista Lucas Veloso, cofundador da Agência Mural de Jornalismo das Periferias, que mora em uma das principais avenidas de Guaianases, bairro localizado no extremo leste da cidade de São Paulo, a Pública ${ }^{30}$ destaca que ele observou que o movimento de transeuntes no local tinha aumentado nas últimas semanas, em comparação à semana do dia 24 de março, quando o governador João Doria (PSDB) instituía a quarentena no estado. "Nas duas primeiras semanas [depois do anúncio do decreto], as ruas estavam de fato mais desertas. O movimento da feira que acontece às quartas, por exemplo, tinha caído muito. Haviam poucas barracas, poucos feirantes. Mas depois da terceira e quarta semanas, percebi que isso mudou”, relata Veloso ${ }^{31}$.

Segundo Veloso, parte da população local não conseguiria parar a sua rotina por questões de renda.

"Muitos dos que moram nas periferias fazem parte dos serviços essenciais. Então, o transporte público de manhã, na estação de trem, não diminuiu tanto. São entregadores, enfermeiros, seguranças. Então, como é um bairro pobre, de periferia, que muitas pessoas estão sujeitas a subempregos, o bairro não consegue parar totalmente", analisa o jornalista ${ }^{32}$.

\footnotetext{
${ }^{29}$ Ibidem.
}

${ }^{30}$ MUNIZ, Bianca; FONSECA, Bruno, PINA, Rute. Em duas semanas, número de negros mortos por coronavírus é cinco vezes maior no Brasil. Pública, 06 de maio de 2020.

${ }^{31}$ Ibidem.

${ }^{32}$ Ibidem. 
Agora, ele observa que até mesmo as pessoas que conseguiam ficar em casa relaxaram as restrições da quarentena.

"As pessoas tinham a esperança, no começo, de conseguir o auxílio emergencial do governo e não precisar sair de casa. Só que tem todas essas burocracias que as pessoas não conseguiram resolver, muitas pessoas não têm qualidade de internet e não conseguiram baixar o aplicativo, aí o dinheiro do auxílio não vem. Isso também é um fator que faz as pessoas voltarem às ruas" $^{\prime 3}$.

A mesma Pública ${ }^{34}$, depois nos fornece explicações sobre os motivos que levam os/as populares negros/as a não respeitarem as regras do isolamento social, considerando que os locais onde vivem mais negros são justamente os com menor Índice de Desenvolvimento Humano Municipal (IDHM).

Os dez bairros com pior IDHM em São Paulo têm mais negros/as que a média da cidade. Já os dez com melhor IDHM têm menos negros que a média. Nos dez bairros com maior número absoluto de mortes, oito têm IDHM considerado médio, abaixo de 0,8 . São justamente esses oito bairros onde a média de moradores negros está acima da média da cidade ${ }^{35}$.

De fato, fica evidente que não se pode pensar a Saúde da População Negra, sem levarse em conta os condicionamentos socioeconômicos, espaciais e raciais.

\section{Necropolítica e corpos negros/as, índios/as e imigrantes africanos/as}

Tivemos acesso, igualmente, aos textos que tratam do impacto da COVID-19 sobre as populações em situação de vulnerabilidade, levando-se em conta o paradigma do genocídio imposto aos/às negros/as e indígenas no Brasil (NASCIMENTO, 1978; FLAUZINA; VARGAS, 2017; MBEMBE, 2018). Além, desses dois grupos sociais os/as quilombolas e imigrantes africanos/as no país merecem uma nota reflexiva.

$\mathrm{O}$ artigo de Milanez e $\mathrm{Vida}^{36}$ denuncia a política de genocídio das populações negras e indígenas no contexto da pandemia de COVID-19.

\footnotetext{
${ }^{33}$ MUNIZ, Bianca; FONSECA, Bruno, PINA, Rute. Em duas semanas, número de negros mortos por coronavírus é cinco vezes maior no Brasil. Pública, 06 de maio de 2020.

${ }^{34}$ Ibidem.

${ }^{35}$ Ibidem.

${ }^{36}$ MILANEZ, Filipe; VIDA, Samuel. Pandemia, racismo e genocídio indígena e negro no Brasil: coronavírus e a política de extermínio. Buenos Aires: CLACSO, 2020. Observatorio del Coronavirus. Disponível em:
} 
Numa sociedade historicamente estruturada pelas assimetrias sociorraciais que atravessam inclusive as classes sociais, definindo graus diferenciados de reconhecimento e acesso aos direitos sociais, civis e políticos elementares, as vítimas preferenciais deste genocídio são, fundamentalmente, as comunidades negras urbanas (favelas, invasões, cortiços, vila, ocupações etc) e rurais (quilombos, comunidades de fundo e fecho de pastos entre outras formas tradicionais de ocupação de territórios) e os diversos grupos étnicos dos povos originários, chamados genericamente de povos indígenas, também vivendo em contexto urbano, em áreas rurais e em florestas.

Um genocídio relacionado tanto à depuração étnica quanto ao interesse na exploração econômica das terras e dos corpos - sejam das trabalhadoras negras submetidas a um regime de superexposição aos riscos de contágio pela manutenção das atividades do trabalho doméstico nas residências das famílias brancas[iv], sejam dos trabalhadores negros do mercado informal, sejam dos trabalhadores indígenas e negros vinculados à produção do agronegócio, sejam das comunidades indígenas e quilombolas espoliadas de suas terras em medidas que visam legalizar garimpos e grilagem aprovadas em meio a pandemia ${ }^{37}$.

Além de problematizar o desconforto com a morte, expressada nos dados estatísticos provenientes de instituições públicas noticiados pela grande mídia e pela generalidade destes dados, Milenez e Vida destacam a responsabilidade de agentes governamentais sobre as medidas genéricas da quarentena e a própria morte provocada pela COVID-19. Denunciam as mortes das populações negras e indígenas causadas pela falta de uma política pública coordenada como manifesto de uma política genocida do governo atual ${ }^{38}$.

Portanto, os dois autores apontaram pautas como caminho para superar o que têm percebido como desafios, no âmbito nacional e internacional, respectivamente:

a) buscar a mobilização de alianças políticas junto à sociedade brasileira e aos movimentos sociais para deter e reverter a atual situação; b) delegar os poderes públicos a adotarem políticas específicas para o enfrentamento da pandemia nas comunidades negras e indígenas; c) convencer as instituições jurídicas como o Ministério Público Federal e os MPE's, a Defensoria Pública da União e as DPE'S, a fim de encararem as suas exigentes atribuições constitucionais e atuarem na defesa dos direitos difusos e coletivos de segmentos sociais pouco escutados ${ }^{39}$.

https:/www.clacso.org/pandemia-racismo-e-genocidio-indigena-e-negro-no-brasil-coronavirus-e-a-politica-deexterminio/. Acesso em: 1 jun. 2020.

${ }^{37}$ MILANEZ, Filipe; VIDA, Samuel. Pandemia, racismo e genocídio indígena e negro no Brasil: coronavírus e a política de extermínio. Buenos Aires: CLACSO, 2020. Observatorio del Coronavirus. Disponível em: https:/www.clacso.org/pandemia-racismo-e-genocidio-indigena-e-negro-no-brasil-coronavirus-e-a-politica-deexterminio/. Acesso em: 1 jun. 2020.

${ }^{38}$ Ibidem.

${ }^{39}$ Ibidem. 
Para o âmbito internacional, apontam, sobretudo, seus órgãos como uma preciosa aliada na luta contra o genocídio indígena e negro no Brasil; investir o esforço comum para acionar as instâncias protetivas dos Direitos Humanos em escala regional, exemplo da OEA, e em escala mundial, caso de ONU, estes como mecanismos de repercutir as denúncias e de responsabilizar os governos e os governantes sobre o genocídio em curso.

Para tanto, os dois autores, em jeito de resumo, consideram que, as políticas de combate à pandemia adotada estão centradas num eixo supostamente geral e universal que, no fundo, toma como medida as circunstâncias de vida e os recursos acessados pelos segmentos brancos da sociedade brasileira. Os apontamentos de Milanez e Vida ${ }^{40}$, seguem desconformando-se com as medidas relativista, escassos da noção de desigualdade, como da intensificação da higienização mediante o uso de álcool em gel, água e sabão, a adesão ao isolamento social, o desenvolvimento de atividades laborais em home office, a suspensão de atividades escolares e de parte dos serviços públicos e atividades econômicas não essenciais, distanciamento social, a sua efetividade centra-se na franja da população branca da sociedade brasileira.

O texto "Covid-19 se alastra pelos quilombos: 17 mortos e 63 casos confirmados" 41 sinaliza que o avanço do novo coronavírus nas periferias e comunidades carentes dos centros urbanos, começa a fazer vítimas também nos territórios quilombolas. A Coordenação Nacional de Articulação das Comunidades Negras Rurais Quilombolas (CONAQ), com o seu monitoramento autônomo, aponta dados preocupantes. A saber, quando se publicava a matéria, nos últimos 20 dias, foram registradas 17 mortes pela COVID-19 e 63 casos confirmados de contágio entre quilombolas. Estavam sendo monitorados, na ocasião, 36 pessoas com sintomas, e havia um óbito suspeito, aguardando agora confirmação de diagnóstico.

Além disso, aponta que havia registro de sete mortes em quilombos do Amapá, três do Pará, dois de Pernambuco, dois de Goiás, um do Rio de Janeiro e um da Bahia. Segundo CONAQ, havia grande subnotificação, como a dificuldade de acesso a exames mesmo por pessoas com sintomas.

\footnotetext{
${ }^{40}$ MILANEZ, Filipe; VIDA, Samuel. Pandemia, racismo e genocídio indígena e negro no Brasil: coronavírus e a política de extermínio. Buenos Aires: CLACSO, 2020. Observatorio del Coronavirus. Disponível em: https:/www.clacso.org/pandemia-racismo-e-genocidio-indigena-e-negro-no-brasil-coronavirus-e-a-politica-deexterminio/. Acesso em: 1 jun. 2020.

${ }^{41}$ OLIVEIRA, Cida. Covid-19 se alastra pelos quilombos: 17 mortos e 63 casos confirmados. Rede Brasil Atual, São Paulo, 6 maio 2020. Disponível em: https://www.redebrasilatual.com.br/saude-eciencia/2020/05/covid-19-quilombolas-17-mortos-e-63-casos-confirmados/. Acesso em: 6 maio 2020.
} 
A CONAQ denuncia igualmente a negligência por parte dos governos locais no Amapá; falta de assistência, de medicamentos, visita de equipes de saúde nas comunidades e de água para as comunidades.

A $R A B$ destaca por fim, a denúncia feita pela CONAQ em relação às ameaças de despejo em Alcântara, do Maranhão e da BR 135, o que constituem em outras ameaças a vida de várias comunidades quilombolas, além da própria morte de COVID-19, e falta de demarcação de terras para proporcionar a autonomia na produção de alimentos ${ }^{42}$.

A população imigrante africana faz igualmente parte dos grupos em situação de vulnerabilidade no contexto da COVID-19. Ao assinar uma matéria no UOL, Guilherme Soares Dias, com título "A pão e água: o drama de africanos que não conseguem auxílio do governo..."43, traz a história da senegalesa Diamu Fallow Diop, conhecida como Mama África, que costuma dizer que foi adotada pelo Brasil.

A matéria em questão revela que além da vida, no Brasil, trazer a Diop boas oportunidades, o mesmo não se pode dizer agora, com a pandemia do novo coronavírus.

Ela - que é do grupo de risco - está isolada em casa e enfrenta dificuldades. Tenta vender suas peças pelo Instagram, mas o movimento é baixo. "Meu gás acabou e fiquei sem poder cozinhar por uma semana. Também não tinha comida. Fiquei três dias comendo pão com água. Não sei como serão os próximos meses."[... $]^{44}$.

Estamos frente a uma história que aponta a falta de acesso ao alimento da parte de uma imigrante africana que já mora há 14 anos no país e trabalhava como vendedora para conseguir a renda e reproduzir a sua vida e de seus/suas familiares. Acontece que temos poucos dados produzidos em relação aos/às imigrantes em geral, e imigrantes africanos/as em particular.

\footnotetext{
${ }^{42}$ OLIVEIRA, Cida. Covid-19 se alastra pelos quilombos: 17 mortos e 63 casos confirmados. Rede Brasil Atual, São Paulo, 6 maio 2020. Disponível em: https://www.redebrasilatual.com.br/saude-eciencia/2020/05/covid-19-quilombolas-17-mortos-e-63-casos-confirmados/. Acesso em: 6 maio 2020.

${ }^{43}$ DIAS, Guilherme Soares. A pão e água: o drama de africanos que não conseguem auxílio do governo. Notícias UOL, São Paulo, 19 maio 2020. Disponível em: https://noticias.uol.com.br/cotidiano/ultimas-noticias/reporterbrasil/2020/05/19/a-pao-e-agua-o-drama-de-africanos-nao-conseguem-auxilio-do-governo.htm. Acesso em: 19 maio 2020 .

${ }^{44}$ Ibidem.
} 
Voa Português com a sua matéria “Angolano é assassinado em São Paulo, testemunha fala em racismo" trouxe à tona a questão do genocídio da população negra, desta vez, especialmente de imigrantes africanos/as ${ }^{45}$.

Um cidadão angolano de 47 anos morreu esfaqueado no domingo, 17, em Itaquera, na Zona Leste de São Paulo, no Brasil.

No momento em que ele foi agredido, dois outros imigrantes que tentaram impedir o ataque ficaram feridos, revela o portal G1, da rede Globo.

Testemunhas afirmam que o suspeito é um auxiliar de mecânico que fugiu.

João Manuel, de 47 anos, trabalhava numa bomba de gasolina.

"Polícias militares foram acionados para atender a ocorrência e, no endereço indicado, encontraram um homem caído, com ferimentos causados por facadas. Próximos estavam dois homens, de 28 e 29 anos, também feridos", disse a Secretaria de Segurança Pública, que confirmou que o caso foi registado no $24^{\circ}$ Distrito Policial (Ponte Rasa) e que investigações para encontrar o suspeito continuam.

$\mathrm{O}$ ataque, de acordo com as mesmas fontes, teve motivação xenófoba e ocorreu após uma discussão sobre o pagamento do auxílio-emergencial federal para imigrantes.

Os dois feridos foram encaminhados ao Hospital Ermelino Matarazzo para atendimento médico e já tiveram alta ${ }^{46}$.

Em seus escritos, Malomalo (2018) vem alertando sobre a necropolítica imposta aos corpos de imigrantes africanos/as no Brasil. O assassinato de João Manoel deu-se, num contexto, de ascensão dos grupos fascistas, racistas de extrema direita no Brasil e a falta de coordenação de uma política nacional de gestão da COVID-19.

$\mathrm{Na}$ fala de um dos dois imigrantes feridos junto com João Manoel, que não quis deixar seu nome registrado, o que motivou o assassinato do imigrante angolano foi o racismo contra imigrante negro: "Eu queria defender o meu irmão. Foi racista, ele deixou claro que foi racismo, porque ele estava a falar que ia matar meu irmão, mas dando risada, tipo como se fosse matar um animal”, relata ${ }^{47}$. Uma das lideranças da comunidade angolana, em São Paulo, nos confidenciou que a morte resultou de uma discussão em torno de ajuda emergencial feita pelo

\footnotetext{
45 ANGOLANO é assassinado em São Paulo, testemunha fala em racismo. VOA Português, 20 maio 2020. Disponível em: https://www.voaportugues.com/a/angolano-\%C3\%A9-assassinado-em-s\%C3\%A3o-paulotestemunha-fala-em-racismo/5427634.html. Acesso em: 24 maio 2020.

${ }^{46}$ ANGOLANO é assassinado em São Paulo, testemunha fala em racismo. VOA Português, 20 de maio 2020.

${ }^{47}$ FIGUEIREIDO, Patrícia. Angolano morre esfaqueado na Zona Leste de SP e 2 ficam feridos; imigrantes deixam suas casas em Itaquera por medo de xenofobia. G1, São Paulo, 19 maio 2020. Disponível em: https:/g1.globo.com/sp/sao-paulo/noticia/2020/05/19/angolano-morre-esfaqueado-na-zona-leste-de-sp-e-2ficam-feridos-imigrantes-deixam-suas-casas-em-itaquera-por-medo-de-xenofobia.ghtml. Acesso em: 19 maio 2020 .
} 
governo aos trabalhadores/as em situação de desemprego. $\mathrm{O}$ assassino, não satisfeito que um imigrante recebesse esse auxílio, chegou a esfaqueá-lo.

\section{Propostas de enfrentamento da pandemia feitas pelas organizações negras}

A pandemia de COVID-19 gerou, na sociedade, uma mobilização que se concretiza através de propostas de diversas organizações sociais e instituições em relação às políticas públicas de saúde. Escolhemos, nessa seção, as propostas de enfrentamentos da pandemia elaboradas pelo do GT Racismo/ABRASCO ${ }^{48}$. São esses 12 pontos:

1. Estabelecer um novo pacto social no qual TODAS AS PESSOAS possam viver com dignidade.

2. Reconhecer a importância e a necessidade do SUS para contenção da COVID-19.

3. Aportar recursos para o pleno funcionamento do SUS, em todas as suas instâncias de formulação, planejamento e gestão de políticas, financiamento, regulação, coordenação, controle e avaliação (do sistema/redes e dos prestadores, públicos ou privados) e prestação direta de serviços.

4. Orientar prefeitos e gestores para aplicar recursos da saúde, considerando o quantitativo e perfil da população negra, de modo a impactar positivamente na melhoria, o controle e a redução de transmissão da COVID-19.

5. (Re)contratar profissionais para atuar na Atenção Primária à Saúde, uma vez que $80 \%$ dos casos da COVID-19 são manejados e necessitam de cuidados neste nível que é, reconhecidamente, hábil e capaz de lidar com grupos vulnerabilizados. 6. Orientar agentes comunitários de saúde para fazer busca ativa de idosos, pessoas com Hipertensão arterial, diabetes, doenças pulmonares obstrutivas crônicas, coenças falciformes e outras doenças consideradas de risco para a COVID-19. 7. Realizar ações de educação em saúde, utilizando materiais educativos (em português, inglês e francês) e levar informações sobre a COVID-19 em parceria com organizações, grupos e coletivos negros nos territórios prioritariamente ocupados por população negra quilombos, favelas, bairros periféricos, terreiros, assentamentos, populações do campo, escolas públicas, invasões, grotas, baixadas, comunidades, vilas, ressacas, mocambos, palafitas, e em situação de rua, entre outros;

\footnotetext{
${ }^{48}$ MARTINS, Pedro. População negra e Covid-19: desigualdades sociais e raciais ainda mais expostas. Rio de Janeiro: ABRASCO, 2020. Disponível: https://www.abrasco.org.br/site/noticias/sistemas-de-saude/populacaonegra-e-covid-19-desigualdades-sociais-e-raciais-ainda-mais-expostas/46338/. Acesso em: 31 maio 2020.
} 
8. No que tange à população em situação de rua é crucial: 8.1. Disponibilizar banheiros públicos abertos e água potável em garrafas descartáveis; Manter restaurantes populares abertos com horário mais amplo e entrega gratuita de alimento;

8.2. Priorizar pessoas em situação de rua nas campanhas de vacinação;

8.3. Aumentar os recursos e ampliar as equipes para os consultórios na rua;

8.4 Distribuir kits com sabão, álcool gel e outros produtos de higiene; 8.5. Acomodar em imóveis apropriados às pessoas em situação de rua que precisam de isolamento;

8.6 Disponibilizar abrigo protegido para pessoas, suas carroças e animais de estimação. 9. Ampliar as condicionalidades nos programas de renda familiar mínima para contemplar: os grupos em contexto de maior vulnerabilidade socioeconômica, risco de adoecimento e morte como: refugiados e migrantes, quilombolas, ribeirinhos, pescadores artesanais, marisqueiras, geraizeiros, povos ciganos acampados, travestis, prostitutas e outros trabalhadores do sexo e população em situação de rua. 10. Inserir a variável raça/cor nas fichas de registro e notificação da Covid-19, divulgar boletins e outras estatísticas oficiais apresentando dados desagregados também por esta variável.

11. Envolver setores como Defensoria Pública, prestadores de serviços, terceiro setor e Organizações não Governamentais para atuarem na mitigação dos impactos negativos da Covid-19 nas populações de maior vulnerabilidade.

12. Convocar e engajar instituições e pessoas de alta renda, para financiar ações de curto, médio e longo prazos voltados para estes grupos.

As propostas do GT Racismo/ABRASCO revelam o profissionalismo e a consciência que os/as especialistas em saúde da população negra têm sobre o que está ocorrendo no país. Caberia aos governantes abrir um caminho de diálogo para que se possa encontrar soluções eficazes acordadas coletivamente.

\section{Considerações finais}

Esse trabalho é uma modesta contribuição sobre os debates em relação à COVID-19 e seu impacto nas populações em situação de extrema vulnerabilidade, de forma particular à população negra. Pautando-se nas fontes documentais e teóricas destacamos os elementos as seguir: 
Indivíduos ou grupos que formam a população negra devem ser compreendidos em termos de cidadãos/ãs brasileiros/as e os/as imigrantes negros/as de todos partes do mundo que residem no país.

Os/as cidadãos/ãs negros/as brasileiros/as são nativos/as ou imigrantes negros/as naturalizados/as. Os/as quilombolas apareceram como uma outra subpopulação de negros/as nascidos/as no Brasil.

Entre os/as imigrantes negros/as, têm-se refugiados/as, exilados/as políticos, residentes temporários/as ou permanentes. Encontra-se igualmente uma parcela de imigrantes negros indocumentados/as, identificados/as pejorativamente como ilegais.

Alertamos o fato de que o não cruzamento das descobertas científicas feitas nas áreas de estudos das relações raciais e estudos migratórios, faz com que as conquistas de políticas públicas para população negra brasileira não alcancem os grupos de imigrantes negros/as.

Dito em outras palavras, a ABRASCO acertou, e isso de forma excepcional, ao tratar das questões que envolvem a população negra, no contexto de COVID-19, ao incluir a população de descendentes de africanos/as escravizados/as no século XVI juntos/as com os/as imigrantes negros/as que vieram de África e outros territórios que formam as diásporas negras no período de pós abolição.

Dessa forma, quando debatemos sobre a inclusão do quesito cor/raça, gênero e moradia, a alta letalidade, as periferias, o isolamento social, o problema de precariedade de vidas negras, queremos sinalizar para o Estado e a sociedade brasileira, que o racismo estrutural e institucional, destacado como um dos maiores entraves no combate à COVID-19, deve ser levado a sério.

Hoje em dia, temos uma literatura consolidada que mostra de que maneira o racismo afeta a vida de pessoas negras ao nascer, (sobre)viver, adoecer e morrer. O contexto de COVID19 que ocasionou uma disputa de classe, trouxe à tona igualmente nossas disputas raciais e de gênero.

Isso significa, em outras palavras, que pessoas negras enfrentam um problema comum nas sociedades multirraciais que nasceram da escravidão. Esse problema tem um nome: racismo. Esse cria desigualdades sociais; empurram negros/as a morar em territórios de periferias e a fazer parte em grande número dos grupos de pessoas desempregadas, ou que trabalham com a informalidade.

Estudos das relações raciais e de migração, que deram suporte a esse trabalho, são ferramentas teórico-metodológicas, geralmente, de tendência pós-marxista. Nesse texto, 
focamos nas populações negras de forma geral, destacando a categoria de raça e racismo deixando de lado o gênero - e a categoria de migração negra/africana.

Com isso, entendemos que pessoas negras devem ser sempre tratadas tomando-se cuidado dos elementos que as aproximam e constituem suas diferenças. Isso nos leva a dizer que a Saúde da População Negra, ao se constituir em área de estudo e de políticas públicas, emergiu para atender as demandas da população negra brasileira. A ABRASCO acertou ao incluir os/as imigrantes na agenda do debate, e nós insistimos que o Estado e a sociedade brasileira desse uma atenção especial à população de imigrantes africanos/as que, nem sempre compreendem, os mecanismos do racismo à brasileira.

\section{REFERENCIAS}

BATISTA, L. E.; WERNECK, J.; LOPES, F. (org.). Saúde da população negra. 2. ed. Brasília, DF: ABPN - Associação Brasileira de Pesquisadores Negros, 2012.

BRASIL, S. A.; TRAD, L. A. B. O movimento negro na construção da Política Nacional de Saúde Integral da População Negra e sua relação com o Estado brasileiro. In: BATISTA, L. E.; WERNECK, J.; LOPES, F. (org.). Saúde da população negra. 2. ed. Brasília, DF: ABPN - Associação Brasileira de Pesquisadores Negros, 2012. p. 62-91.

DOSSIÊ TEMÁTICO. A importância das comissões de heteroidentificação para a garantia das ações afirmativas destinadas aos negros e negras nas universidades públicas brasileiras. Revista da ABPN, Uberlândia, v. 11, n. 29, p. 1-242, 2019.

FLAUZINA, A. L. P.; VARGAS, J. H. C. Motim: horizontes do genocídio antinegro na diáspora. Brasília: Prado Negro, 2017.

GIL, Antônio Carlos. Como elaborar projetos de pesquisa. São Paulo: Editora Atlas, 1996.

GOMES, N. Alguns termos e conceitos presentes no debate sobre relações raciais no Brasil: Uma breve discussão. In: BRASIL. Secretaria de Educação Continuada, Alfabetização e Diversidade (SECAD). Educação anti-racista: caminhos abertos pela lei Federal na 10.639/03. Brasília: Ministério da Educação, Secretaria de Educação Continuada, Alfabetização e Diversidade, 2005. p. 39-62.

GOMES, R. Análise e interpretação de dados de pesquisa qualitativa. In: DESLANDES, S. F. Pesquisa social: teoria, método e criatividade. 31. ed. Petrópolis: Vozes, 2012. p. 79-107.

GONÇALVES, L. A.; SILVA, P. B. G. Multiculturalismo e educação: do protesto de rua a propostas e políticas. Educação e Pesquisa, São Paulo, v. 29, n. 1, p. 109-123, 2003.

GONÇALVES, L. A.; SILVA, P. B. G. O jogo das diferenças: o multiculturalismo e seus contextos. 4. ed. Belo Horizonte: Autêntica, 2006.

GUIMARÃES, A. S. A. A questão racial na política brasileira (os últimos quinze anos). Tempo Social - Revista da Universidade de São Paulo, São Paulo, v. 13, n. 2, p. 121-142, 2001. 
JACCOUD, L. B.; BEGHIN, N. Desigualdades raciais no Brasil: um balanço da intervenção governamental. Brasília: IPEA: 2002.

JACCOUD, L. B.; BEGHIN, N. O combate ao racismo e à desigualdade: O desafio das políticas públicas de promoção da igualdade racial. In: THEODORO, M. et al. (org.). As políticas públicas e a desigualdade racial no Brasil: 120 anos após a abolição. 2. ed. Brasília: IPEA, 2009. p. 135-170.

MALOMALO, B. Mobilização política dos/as imigrantes africanos/as pela conquista de seus direitos no Ceará (2012-2016). Revista de Humanidades. Série Letras, São João da Boa Vista, v. 3, n. 1, p. 57-84, 2017.

MALOMALO, B. Imigrantes africanos/as na contemporaneidade brasileira: Uma agenda panafricanista na década internacional de afrodescendentes. In: KOMINEK, A. M. V.; VANILI, A. C. Roteiros da diáspora: caminhos para enfrentamento ao racismo no Brasil. Porto Alegre: Editora Fi, 2018. p. 467-500.

MALOMALO, B. Repensar o multiculturalismo e o desenvolvimento no Brasil: políticas públicas de ações afirmativas para a população negra (1995-2009). 2010. 482 f. Tese (Doutorado em Sociologia) - Faculdade de Ciências e Letras, Universidade Estadual Paulista "Júlio De Mesquita Filho", Araraquara, 2010.

MBEMBE, A. Necropolítica: biopoder, soberania, estado de exceção, política da morte. Tradução: Renata Santini. São Paulo: N-1 Edições, 2018. 80 p.

MEDRADO, B. Textos em cena: a mídia como uma prática discursiva. In: SPINK, J. M. (org.). Práticas discursivas e reprodução de sentidos no cotidiano: aproximações teóricas e metodológicas. São Paulo: Cortez, 1999. p. 243-271.

NASCIMENTO, A. O genocídio do povo negro brasileiro: processo de um racismo mascarado. Rio de Janeiro: Terra e Paz, 1978.

NOGUEIRA, O. Tanto preto quanto branco: estudos de relações raciais. São Paulo: T.A. Queiroz, 1985.

PAIXÃO, M. 500 anos de solidão: estudos sobre desigualdades raciais no Brasil. Curitiba: Appris, 2013.

PAIXÃO, M. Querelas do Brasil: contextos, contendas e conteúdo dos dez anos de Observatório da Cidadania. In: OBSERVATÓRIO DA CIDADANIA. Relatório 2007:

dignidade e direitos: seguridade social como direito universal. Rio de Janeiro: IBASE, 2007. p. 1-122. 1 CD-ROM.

PAIXÃO, M. Manifesto anti-racista: ideias em prol de uma utopia chamada Brasil. Rio de Janeiro: DP\&A/ LPP/UERJ, 2006.

PAIXÃO, M. Nada haver ou tudo a ver? Diálogo entre a questão do desenvolvimento econômico e das relações raciais no Brasil. In: CONFERÊNCIA INTERNACIONAL DA REDE DE ESTUDOS DE AÇÃO AFIRMATIVA, 1., 2005, Rio de Janeiro. Anais [...]. Rio de Janeiro: Universidade Candido Mendes, 2005. p. 299-324.

PAIXÃO, M. Desenvolvimento humano e relações raciais. Rio de Janeiro: DP\&A, 2003.

PAIXÃO, M.; CARVANO, L. M. (org.). Relatório anual das desigualdades raciais no Brasil 2007-2008. Rio de Janeiro: Gramond, Laeser, 2008. 
SOARES FILHO, A. M. O recorte étnico-racial nos Sistemas de Informações em Saúde do Brasil: potencialidades para a tomada de decisão. In: BATISTA, L. E.; WERNECK, J.; LOPES, F. (org.). Saúde da população negra. 2. ed. Brasília, DF: ABPN - Associação Brasileira de Pesquisadores Negros, 2012. p. 34-61.

THEODORO, M. (org.). As políticas públicas e a desigualdade racial no Brasil: 120 anos após a abolição. 2. ed. Brasília: IPEA, 2008.

\title{
NOTES ON THE IMPACT OF COVID-19 ON THE HEALTH OF BLACK POPULATION
}

\begin{abstract}
There is a lot of damage that the COVID-19 pandemic has caused and it is too early to know its real cost, especially when governments have difficulties to coordinate effective policies to combat the disease, which avoid the negative impact on the general population and, particularly, groups in situations of greater vulnerability. This work reflects on the impact of COVID-19 on the black Brazilian population, starting with the debates made by specialists in Health of the Black Population and other social agents in the period from April to May 2020. It is a documentary and bibliographic research that focuses on thematic interpretation of content, divided into three parts: first, the delimitation of what is understood in this work by the black population; later, the discussion between the health of the black population and public policies in Brazil; and finally, the systematization of the debate on the impact on the black population of COVID-19, highlighting the issues of inclusion by color / race, gender and housing, lethality, impact on the periphery, social isolation and the problem of precarious black lives. Considerations about necropolitics and black bodies, Indians and African immigrants are addressed; and the proposals for tackling the pandemic made by the Brazilian Association of Public Health (ABRASCO).
\end{abstract}

Keywords: Black population; COVID-19; Population Health; Black Lives.

\section{NOTAS SOBRE EL IMPACTO DE COVID-19 EN LA SALUD DE POBLACIÓN NEGRA}

\begin{abstract}
Resumen
Muchos son los daños que ha ocasionado la pandemia de COVID-19 y es prematuro saber su costo real, todavía más cuando los gobiernos tienen dificultades para coordinar políticas efectivas de combate a la enfermedad, que impidan el impacto negativo en la población general $\mathrm{y}$, en particular, en los grupos en situación de más vulnerabilidad. Este trabajo reflexiona sobre el impacto de la COVID-19 en la población negra brasileña, comenzando con los debates hechos por especialistas en Salud de la Población Negra y otros agentes sociales en el período abril-mayo de 2020. Es una investigación documental y bibliográfica que se enfoca en la interpretación temática de contenido, dividida en tres partes: primero, la delimitación de lo que se entiende en este trabajo por población negra; posteriormente, la discusión entre salud de la población negra y políticas públicas en Brasil; y finalmente, la sistematización del debate
\end{abstract}


sobre el impacto en la población negra por COVID-19, destacando las cuestiones de inclusión por color/raza, género y vivienda, letalidad, impacto en las periferia, aislamiento social y problema de precariedad de vidas negras. Se abordan reflexiones sobre necro-política y cuerpos negros/as, indígenas e inmigrantes africanos/as; y las propuestas de enfrentamiento contra la pandemia hechas por la Asociación Brasileña de Salud Colectiva (ABRASCO).

Palabras claves: Población Negra; COVID-19; Salud de la Población; Vidas Negras. 